\title{
A V-Band MMIC SPDT Passive HEMT Switch Using Impedance Transformation Networks
}

\author{
Yu-Jiu Wang*, Kun-You Lin ${ }^{+}$, Dow-Chih Niu", and Huei Wang** \\ *Dept. of Electrical Engineering and ${ }^{+}$Graduate Institute of Communication Engineering \\ National Taiwan University, Taipei, Taiwan, 10617, ROC \\ ${ }^{\#}$ Chung-Shan Institute of Science and Technology \\ Lung-Tan, Tao-Yuan, Taiwan, ROC
}

\begin{abstract}
A V-Band MMIC single pole double throw (SPDT) switch using GaAs PHEMT process is designed, fabricated and tested. In contrast to the conventional resonant-type switch design method, this passive FET switch circuit utilizes impedance transformation to compensate the drain-source capacitance effect for the off-state in millimeter-wave frequency range. This SPDT switch has a measured isolation better than $30 \mathrm{~dB}$ for the off-state and 4 dB insertion loss for the on-state from $53 \mathrm{GHz}$ to $61 \mathrm{GHz}$. The isolation performance of this design approach outmatches previously published FET switches in this frequency range.
\end{abstract}

Index Terms- V-Band, PHEMT, SPDT, MMIC, switches

\section{INTRODUCTION}

Switches are important components in millimeter-wave (MMW) systems. Monolithic PIN diode switches has demonstrated good performance at MMW frequency [1]. However, since PIN diode process is not compatible with HEMT MMIC process, passive HEMT (or FET) switches are still very popular [2]-[6], because they can be integrated with the other major building blocks in a MMW transmit/receive (T/R) module, which are mostly fabricated using HEMT MMIC process. Most MMW monolithic passive HEMT switches reported to date were resonant-type FET switches [2]-[4], with the isolation performance lower than $30 \mathrm{~dB}$. High isolation Q-band HEMT switches reported in [5], utilized two-stage un-terminated quarter wavelength shunt design to achieve up to $50 \mathrm{~dB}$ isolation. However, a huge chip area is required in such design. Recently, compact dc-60 GHz HJFET MMIC switches [6] were reported with reasonable isolation performance, but they required special process/layout for the ohmic electrode-sharing technology in the HEMT devices.

In this paper, a new HEMT switch design using impedance transformation concept is proposed in contrast to the conventional resonant-type design for the MMW frequency. A V-band single pole double throw (SPDT) MMIC switch using standard $0.15-\square \mathrm{m}$ GaAs PHEMT foundry process is designed, fabricated, and tested to verify this design concept. It demonstrated a measured on-state insertion loss of less than $4 \mathrm{~dB}$ with an off-state isolation of better than $30 \mathrm{~dB}$ from 53 to $61 \mathrm{GHz}$. The isolation performance outmatches the reported $\mathrm{V}$-band MMIC FET switches [4],[6], with a slightly higher on-state insertion loss.

\section{DEVICE CHARACTERISTICS AND MMIC PROCESS}

The HEMT device used in this design is TRW standard $0.15-[\mathrm{m}$ high linearity InGaAs/AlGaAs/GaAs PHEMT MMIC process. The HEMT device has a typical unit current gain cutoff frequency $\left(\mathrm{f}_{\mathrm{T}}\right)$ of $70 \mathrm{GHz}$ and maximum oscillation frequency $\left(\mathrm{f}_{\max }\right)$ of $110 \mathrm{GHz}$, with a peak dc transconductance $\left(G_{\mathrm{m}}\right)$ of $580 \mathrm{mS} / \mathrm{mm}$. The gate-drain breakdown voltage is $8 \mathrm{~V}$, and the drain current at peak $\mathrm{G}_{\mathrm{m}}\left(\mathrm{I}_{\mathrm{dspk}}\right)$ at $5-\mathrm{V}$ drain-source voltage is $280 \mathrm{~mA} / \mathrm{mm}$. Other passive components include thin-film resistors, MIM capacitors, spiral inductors, and air-bridges. The wafer is thinned to 4-mil for the gold plating of the backside and reactive ion etching via holes are used for dc grounding.

\section{CIRCUIT DESIGN}

The dimension of HEMT device selected for this MMIC design is $200-\square \mathrm{m}$ total gate width with four finger. The equivalent on-state $\left(\mathrm{V}_{\mathrm{gs}}=+0.5 \mathrm{~V}\right)$ series resistance of this passive HEMT is 2.9 . $\square$ while the off-state $\left(\mathrm{V}_{\mathrm{gs}}=-3\right.$ $\mathrm{V})$ series capacitance is $27 \mathrm{fF}$. In previously reported MMW designs, the FET with a resonant inductor was either directly shunt to ground [2]-[4], or shunt with a quarter-wave length line [5], as shown in Fig. 1. In our design, the resonant inductor is replaced by a series impedance transformation network to the HEMT device and then the HEMT with the transformation network is 
shunt to ground to serve the switching function. The schematic diagram is presented in Fig. 2.

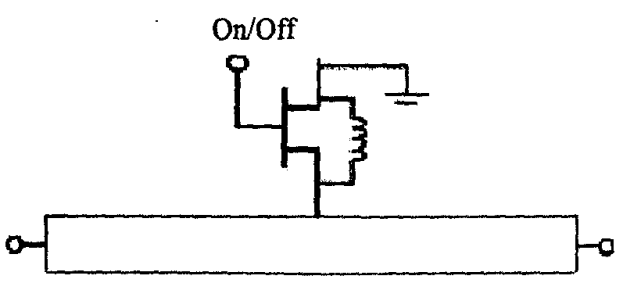

(a)

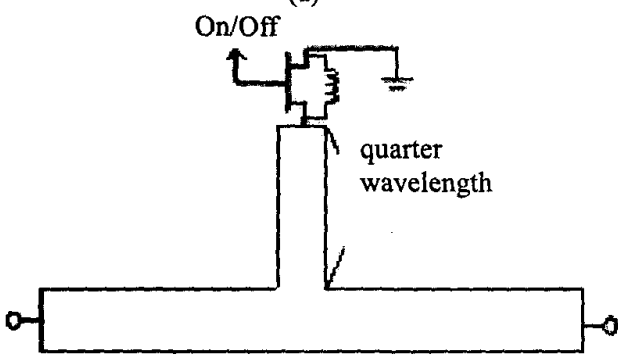

(b)

Fig. 1. (a) The schematic representations of shunt resonant FET, and (b) shunt resonant FET with quarter-wave length line.

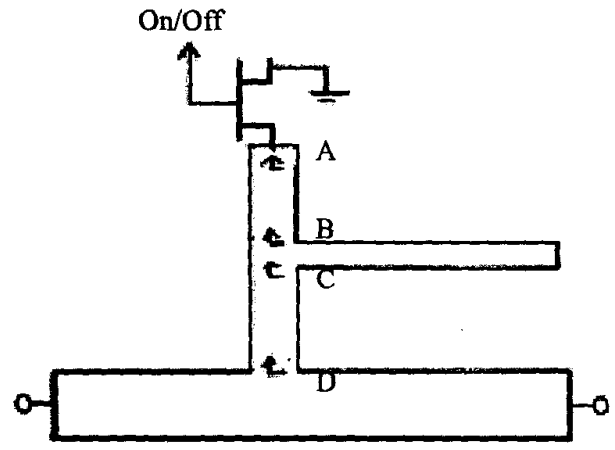

Fig. 2. Schematic diagram of a shunt reactively matched passive FET switch with impedance transformation network.

To design the impedance transformation network for the passive HEMT switch, the input impedance of both on and off-states need to be considered simultaneously. The matching network shown in Fig. 2 is composed with a series high impedance line, followed by an open stub and another series high impedance line. The input impedance values at $60 \mathrm{GHz}$ looking into points $A, B, C, D$ in Fig. 2 for both on- and off-states were indicated on the Smith chart shown in Fig. 3. As observed on the Smith chart, the input impedance values of both the on- and off-states for a non-resonant shunt FET (point A's) can be successfully transferred to a near short (small resistor) and near open (point D's), respectively, through the same impedance transformation network by carefully selecting the length of each high impedance line.

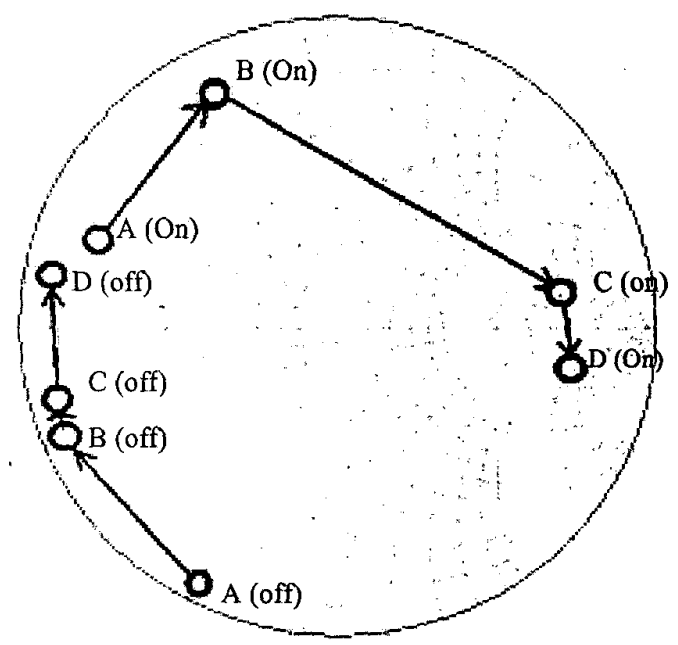

Fig. 3. The input impedances looking into points A, B, C, D of the passive switch with impedance transformation network in Fig. 2 on the Smith chart for both on- and off-states at $60 \mathrm{GHz}$

The complete SPDT switch circuit schematic diagram is shown in Fig. 4. In each path, two cascaded shunt passive HEMTs devices with the impedance transformation networks were used to enhance the isolation. The chip photograph is shown in Fig. 5, with a chip size of $2 \mathrm{~mm} \times 1 \mathrm{~mm}$.

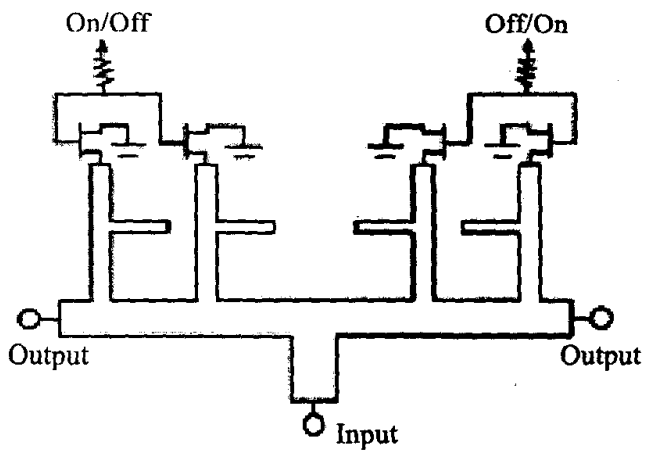

Fig. 4. The complete schematic diagram of the V-band SPDT switch using shunt passive HEMT with impedance transformation network. 


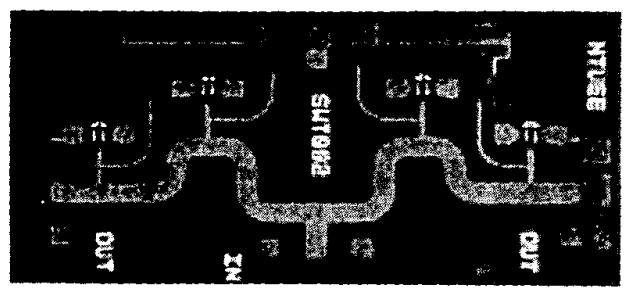

Fig. 5. Chip photograph of the V-band MMIC SPDT switch, with a chip size of $2 \mathrm{~mm} \times 1 \mathrm{~mm}$.

\section{CIRCUIT MEASUREMENT}

The V-band SPDT MMIC switch is measured via on-wafer probing. The on- and off-states two-port small-signal S-parameters of each path were obtained by terminating the output port of the other path. Both on-state insertion loss and off-state isolation from 50 to 70 $\mathrm{GHz}$ are plotted in Fig. 6. The control voltage for each path is $+0.5 \mathrm{~V}$ for the on-state and $-3 \mathrm{~V}$ for the off-state. The insertion loss is between 3.5 and $4 \mathrm{~dB}$ and the isolation is better than $30 \mathrm{~dB}$ from 53 to $61 \mathrm{GHz}$. The best isolation is $35 \mathrm{~dB}$ at around $56.5 \mathrm{GHz}$.

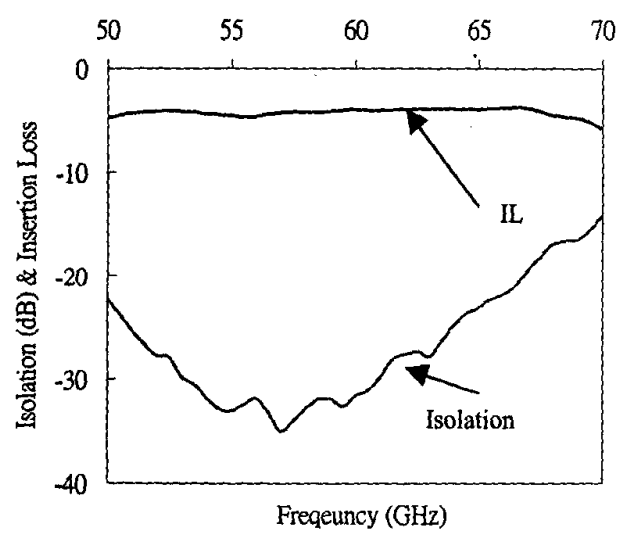

Fig. 6. Measured on-state $\left(V_{d s}=0, V_{g s}=+0.5 \mathrm{~V}\right)$ insertion loss and off-state $\left(V_{d s}=0, V_{g s}=-3 \mathrm{~V}\right)$ isolation of the V-band MMIC SPDT chip from 50 to $70 \mathrm{GHz}$.

Table 1 summarizes the previously reported performance and features of passive FET MMIC switches from $\mathrm{Ka-}$ to $\mathrm{V}$-band. The isolation of the Q-band switches [5] achieved the best isolation at the cost of large chip area. For V-band switches, the isolation performance in this work outmatches the other designs at similar frequencies [4], [6] with a comparable chip size of [4], and a slightly higher on-state insertion loss. It is also observed that the isolation of this passive FET switch using impedance transformation is better than those of the resonant type MMIC FET switches [2]-[4].

\section{SUMMARY}

We have demonstrated a passive FET design using impedance transformation in MMW frequency range. A V-band SPDT MMIC switch using HEMT process was designed and fabricated to verify this design concept. The MMIC chip has a measured isolation of better than 30 dB from 53-61 GHz, which outmatches the conventional resonant type FET MMIC switches at similar frequencies.

\section{ACKNOWLEDGEMENT}

This is work is supported in part by Research Projects of National Science Council of Republic of China. (Project no.: NSC 89-2815-C-002-126-E, NSC 89-2219-E-002-042 and NSC 89-2213-E-002-178.) The MMIC foundry service is provided by TRW Inc. through the Chip Implement Center (CIC) in Taiwan. The authors would like to thank Dr. Ying-Zung Juang of CIC and Mr. Chieh-Chyau Liu of Airwave Technology for their MMIC foundry coordination effort.

\section{REFERENCES}

[1] E. Alekseev, D. Pavlidis, " $77 \mathrm{GHz}$ high-isolation coplanar transmit-receive switch using InGaAs/InP PIN diodes", in 1998 Gallium Arsenide Integrated Circuit (GaAs IC) Symposium, pp. 177-180.

[2] M. J. Schindler and A. Morris, "DC-40 GHz and 20-40 GHz MMIC SPDT switches," IEEE Trans. on Microwave Theory Tech., vol. MTT-35, no. 12, pp. 1486-1493, Dec. 1987.

[3] P. Bermkopf, M. Schindler, and A. Bertrand, "A high power $\mathrm{K} / \mathrm{Ka}$-band monolithic $\mathrm{T} / \mathrm{R}$ switch," in 1991 IEEE Microwave \& Millimeter-wave Monolithic Cincuits Symposium Digest, pp.15-18, June 1991.

[4] G. L. Lan, D. L. Dunn, J. C. Chen, C. K. Pao and D. C. Wang. "A High Performance V-Band Monolithic FET Transmit-Receive Switch," in 1988 IEEE Microwave \& Millimeter-wave Monolithic Circuits Symposium Digest, pp. 99-101, June 1988.

[5] D. L. Ingram, K. Cha, K. Hubbard, and R. Lai, "Q-band high isolation GaAs HEMT switches," in 1996 IEEE GaAs IC Symp. Dig., Orlando, FL, pp. 289-282, Nov. 1996.

[6] H. Mizutani, N. Funabashi, M. Kuzuhara, Y. Takayama, "Compact DC-60-GHz HJFET MMIC switches using ohmic electrode-sharing technology," IEEE Trans. on Microwave Theory and Tech., vol. 46, no. 11, pp. 1597-1603, Nov. 1998. 


\begin{tabular}{|c|c|c|c|c|c|c|}
\hline Author & $\begin{array}{c}\text { Schindler et al. } \\
\text { (Raytheon) [2] }\end{array}$ & $\begin{array}{c}\text { Bernkopf et al. } \\
\text { (Raytheon) [3] }\end{array}$ & $\begin{array}{c}\text { Lan et al. } \\
\text { (Hughes) [4] }\end{array}$ & $\begin{array}{c}\text { Ingram et al } \\
\text { (TRW) [5] }\end{array}$ & $\begin{array}{c}\text { Mizutani } \\
\text { (NEC) [6] }\end{array}$ & This work \\
\hline Device & MESFET & MESFET & MESFET & GaAs HEMT & HJFET & GaAs HEMT \\
\hline $\begin{array}{c}\text { Design } \\
\text { Approach }\end{array}$ & Shunt & Shunt & Shunt & $\begin{array}{c}\text { Quarter } \\
\text { wave-length } \\
\text { Shunt } \\
\text { Ohmic }\end{array}$ & $\begin{array}{c}\text { Series-shunt; } \\
\text { Electrode-Sharing } \\
\text { Technology } \\
\text { (special process/ } \\
\text { layout required) }\end{array}$ & $\begin{array}{c}\text { Shunt with } \\
\text { impedance } \\
\text { transformation } \\
\text { network }\end{array}$ \\
\hline $\begin{array}{c}\text { Number of } \\
\text { stages }\end{array}$ & 2 & 2 & 2 & 2 & - & 2 \\
\hline $\begin{array}{c}\text { Freq. Range } \\
\text { (GHz) }\end{array}$ & $20-40$ & $15-30$ & $56-64$ & $42-46$ & $\begin{array}{c}\text { DC-40(SPDT) } \\
\text { DC-60 (SPSP) }\end{array}$ & $53-61$ \\
\hline $\begin{array}{c}\text { Insertion Loss } \\
\text { (dB) }\end{array}$ & 2 @ 40GHz & $2-3$ & $<3.2$ & $<1.6$ & $<3.5$ (SPDT) & $<4$ \\
\hline Isolation (dB) & $25-28$ & $>20$ & $>23$ & $35-50$ & $>25$ (SPDT) & $>30$ \\
\hline $\begin{array}{c}\text { Chip Size } \\
\text { (mm) }\end{array}$ & - & $2 \times 2.2$ & $0.8 \times 2.45$ & $5 \times 2$ & $0.86 \times 0.64$ & $2 \times 1$ \\
\hline
\end{tabular}

Table 1. Summary of the performance and features of previously reported passive HEMT MMIC switches and this work from Ka- to V-band. 